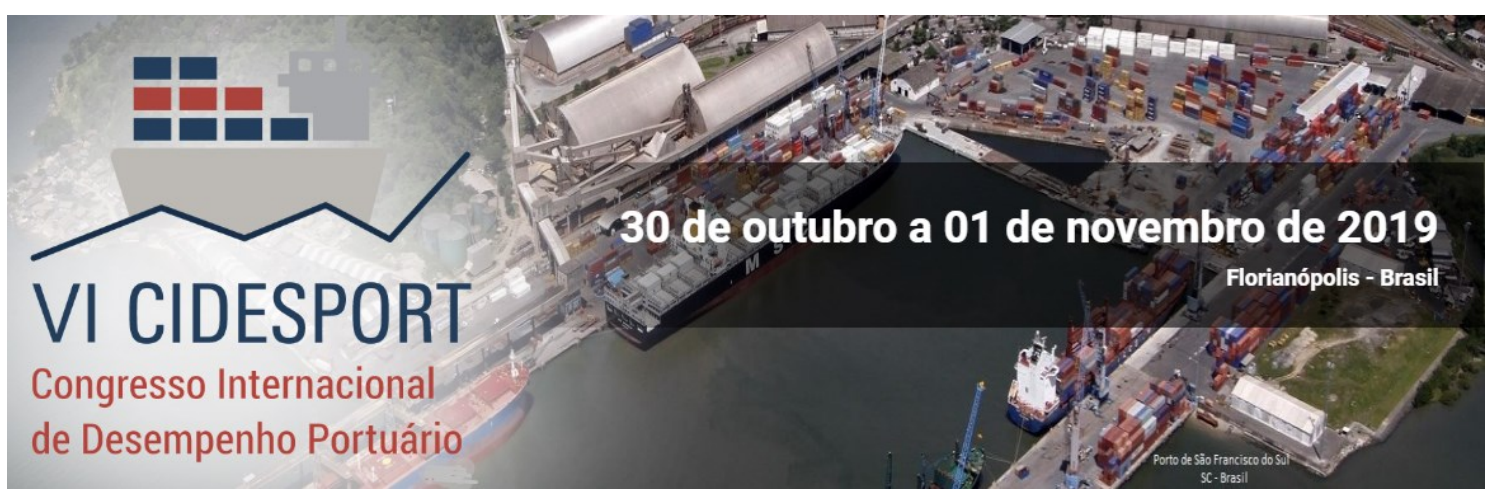

\title{
GERENCIAMENTO DE ESCOPO DO PROJETO DE IMPLANTAÇÃO DA NORMA ISO 9001: 2015 NA DIRETORIA DE OPERAÇÕES DA EMPRESA MARANHENSE DE ADMINISTRAÇÃO PORTUÁRIA - EMAP
}

\author{
Alexandre Sá dos Santos \\ Universidade Federal do Pará
}

\section{Ana Carolina Oliveira Maciel Universidade Federal do Pará}

Resumo: No mundo competitivo em que vivemos as empresas não podem se dá ao luxo de errar na tomada de suas decisões, pois pode significar a falência da companhia. Por esta razão tem-se investido cada vez mais em tecnologias e ferramentas que possibilitem um maior controle e melhor gestão de seus recursos (financeiros, pessoais, materiais, informacionais, entre outros), visando desta forma aumentar a probabilidade de sucesso na implantação de projetos. Este trabalho tem por finalidade demonstrar a importância da utilização dos processos, ferramentas e técnicas do gerenciamento de escopo, segundo recomendação do Project Management Institute - PMI, para definir e gerenciar o escopo de um projeto de implantação da Norma ISO 9001: 2015 na Diretoria de Operações da Empresa Maranhense de Administração Portuária - EMAP. Além de fornecer como material de apoio a outros profissionais os documentos gerados em cada fase do gerenciamento de escopo como o Termo de Abertura do Projeto, o Plano Gerenciamento do Escopo, Matriz de Rastreabilidade de Requisitos, Termo de Aceite das Entregas, Estrutura Analítica de Projeto - EAP, Dicionário da EAP e Formulário de Solicitação de Mudanças do Escopo, pois muito é falado sobre a teoria do Gerenciamento de Escopo, mas pouco é mostrado na prática.

Palavras-Chave: Projeto. Gerenciamento. Escopo. Processos.

\section{INTRODUÇÃO}

Este trabalho tem como principal objetivo fazer o acompanhamento no gerenciamento do escopo de projeto da implantação da Norma ISO 9001: 2015 na Diretoria de Operações da Empresa Maranhense de Administração Portuária - EMAP. A diretoria objeto do estudo é composta por 50 integrantes, os quais representam $22,5 \%$ do efetivo da empresa e contribuiu com um percentual médio anual de $66,72 \%$ da receita bruta recolhida pela companhia. O estudo de caso deste trabalho apresentará algumas entradas, ferramentas e técnicas e saídas relacionadas aos processos da área do conhecimento descritas no Guia PMBOK 2013 5ed do Project Management Institute (PMI). Serão apresentados os formulários desenvolvidos para acompanhamento de cada etapa do projeto.

\footnotetext{
*A revisão gramatical, ortográfica, ABNT ou APA foi realizada pelos autores.
} 
VI CIDESPORT/2019

Congresso Internacional

de Desempenho Portuário

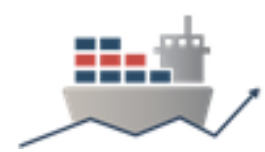

\section{REFERENCIAL TEÓRICO}

\subsection{Literatura Consultada}

Para o desenvolvimento do estudo em questão a literatura consultada acerca da metodologia adotada para a formulação de planos de gerenciamento de projeto teve como principal referência o PMBOK (Project Management Body of Knowledge) publicado pelo Instituto de Gerenciamento de Projetos (Project Management Institute $P M I)$ que foi criado em 1969 na Pensilvânia - EUA, onde um grupo de profissionais se reuniu para discutir e compilar as melhores práticas do gerenciamento de projetos. $\mathrm{O}$ PMBOK é um guia de Conhecimentos em Gerenciamento de Projetos publicado pelo PMI em 1996, que aborda dez áreas de conhecimento, distribuídas em cincos grupos de processos para fomentar e promover uma padronização de integração de processos para estruturar um projeto, atualmente este guia encontra-se em sua $6^{\mathrm{a}}$ edição.

Um projeto pode ser definido como um esforço temporário empreendido para criar um produto, serviço ou resultado exclusivo (PMBOK, 2013 5ed.) ". Diante do grande volume de projetos criados e desenvolvidos pelas empresas o Gerenciamento de Projetos tornou-se uma ferramenta fundamental nas instituições para conferir aos projetos maior probabilidade de sucesso através de um correto planejamento e uma eficiente execução, o que contribui diretamente para que a organização alcance seus objetivos estratégicos os quais são de suma importância para a saúde da empresa.

Segundo SOTILLE (2014), o gerenciamento do escopo do projeto é o processo que assegura que este contemple todo o trabalho necessário, e somente o trabalho necessário, para que termine com sucesso. O gerenciamento do escopo é a base para o planejamento do projeto e para a criação de sua linha de base, e deve ser conduzido de forma precisa, uma vez que forma a base do trabalho a ser desenvolvido no projeto (e a ser pago pelo cliente).

Segundo VARGAS (2014), o gerenciamento de projetos não propõe nada revolucionário e novo. Sua proposta é estabelecer um processo estruturado e lógico para lidar com eventos que se caracterizam pela novidade, complexidade e dinâmica ambiental.

\section{BREVE HISTÓRICO DA CERTIFICAÇÃO DO PORTO DO ITAQUI ISO 9001}

A Emap obteve a sua primeira certificação na ISO9001 no ano de 2008. Para apoio a implementação desta norma o Porto do Itaqui contratou uma consultoria do SENAI de Itajaí. O processo de implementação dos requisitos da ISO9001 levou aproximadamente um ano.

Em 2015 a norma ISO9001 passou por uma atualização mudando da versão 2008 para 2015, modificado de forma estruturante os requisitos desta ISO. A partir de 2015, as empresas certificadas teriam três anos para migrar da versão 2008 para 2015. Caso as empresas não fizessem esta modificação até o ano de 2018 , o certificado perderia a validade.

A EMAP implementou a nova norma sem apoio de consultoria externa, apenas com a coordenação da equipe da Qualidade. Em 2017, a EMAP obteve a certificação na ISO9001 versão 2015 e ainda fez um upgrade no escopo: a inclusão do terminal da ponta da espera. 
VI CIDESPORT/2019

Congresso Internacional

de Desempenho Portuário

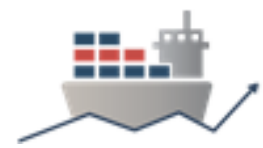

\section{METODOLOGIA APLICADA}

A metodologia utilizada tem uma abordagem descritiva e aplicativa, conta com uma pesquisa bibliográfica e estudo de caso participante relacionado ao tema gerenciamento de projetos, em específico a parte de escopo com a finalidade de demonstrar e instruir a aplicação das boas práticas do gerenciamento de projeto na implantação da Norma 9001:2015 em uma empresa pública do setor portuário.

\section{ESTUDO DE CASO}

\subsection{Contextualização do Porto do Itaqui}

O Porto do Itaqui tem sido um elemento chave na integração dos diversos setores da economia regional, reflexo também de sua multimodalidade e malha viária, que influência diretamente no planejamento do uso e ocupação do solo em sua área de influência direta e indireta (Figura 01). De acordo com informações da Agência Nacional de Transportes Aquaviários - ANTAQ, o Porto do Itaqui faz parte do maior complexo portuário do Brasil em volume de carga movimentado, ocupa o terceiro lugar no ranking dos portos públicos, tanto na movimentação de granel líquido (combustíveis e químicos) quanto na movimentação de grãos (soja, milho e farelo de soja). Além de destacar-se como líder em exportação de grãos entre os portos do arco norte (portos acima do paralelo 16), com $32 \%$ do market share deste segmento, e consequentemente, também líder na importação dos fertilizantes utilizados para o preparo da terra para o grão.

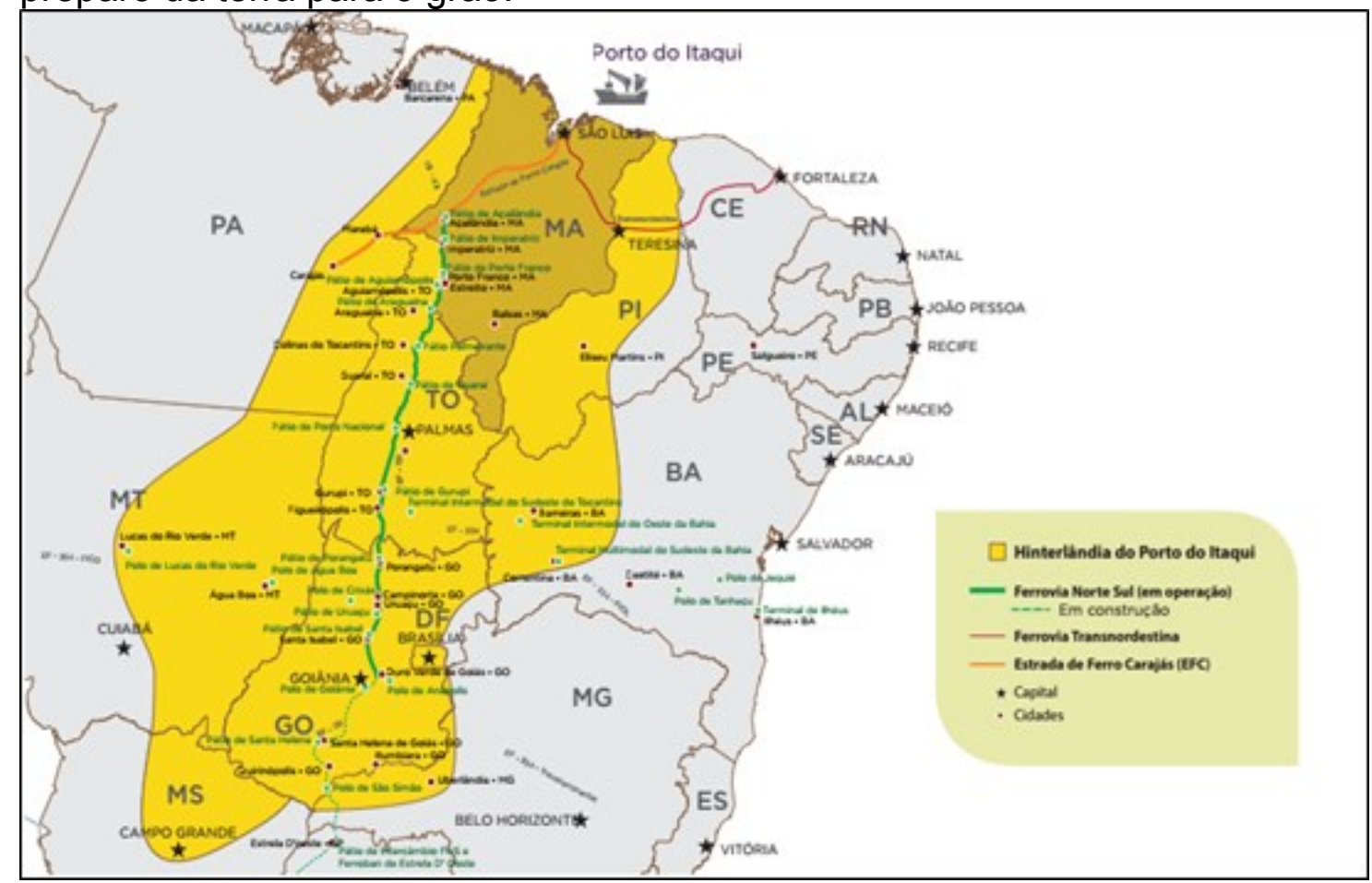

Figura 01 - Hinterlândia do Porto do Itaqui.

Fonte: Apresentação Comercial da EMAP, 2019. 
VI CIDESPORT/2019

Congresso Internacional

de Desempenho Portuário

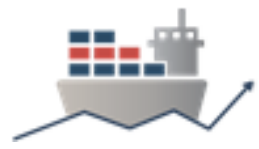

O Porto do Itaqui conta com uma infraestrutura de acostagem de oito berços, sendo três deles dedicados à movimentação de granéis líquidos e cinco multipropósitos (Figura 02).

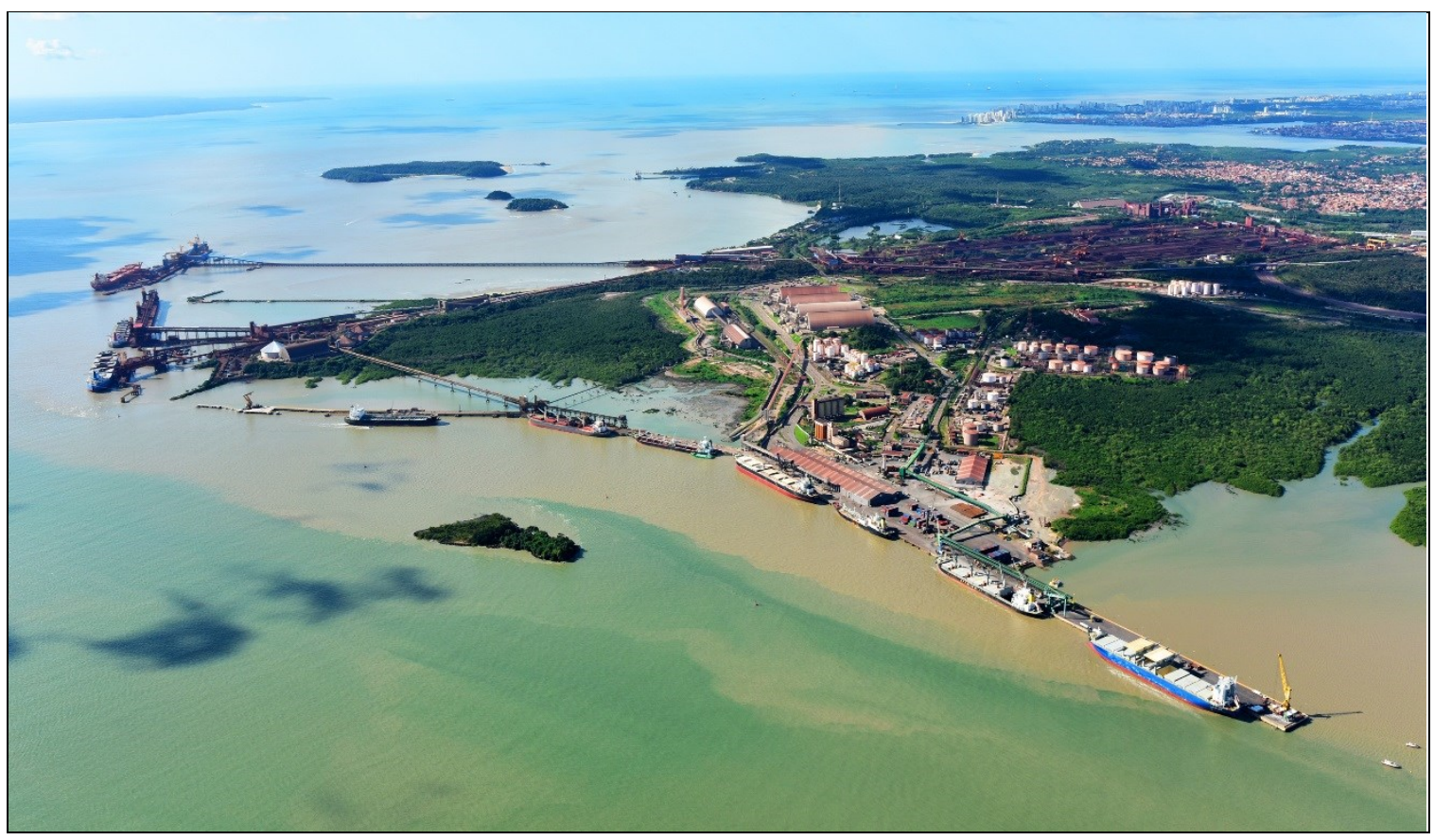

Figura 02 - Infraestrutura de acostagem do Porto do Itaqui.

Fonte: Apresentação Comercial da EMAP, 2019.

O Porto do Itaqui possui ainda, uma robusta infraestrutura terrestre que conta com quatro sistemas mecanizados de operações de cais, capacidade estática de tancagem de $329.884 \mathrm{~m}^{3}$. A capacidade dinâmica de movimentação de grãos é de 10 milhões de toneladas por ano, considerando os volumes movimentados pelo TEGRAM e pela VLi na área do Porto Organizado. Também conta com capacidade dinâmica de 900 mil toneladas de concentrado de cobre por ano, além de pátios e armazéns que são utilizados para movimentar as demais cargas como: celulose, fertilizante, manganês, trilho, dormente, clínquer, carga de projeto, contêiner, entre outras.

Em função do aumento na demanda de cargas, o Porto do Itaqui vem expandindo sua infraestrutura marítima e terrestre por meio de recursos próprios e parcerias público/privadas que contabilizam aproximadamente $\mathrm{R} \$ 700$ milhões em investimentos, e com a perspectiva de mais $\mathrm{R} \$ 540$ milhões de investimentos para os próximos anos com a licitação de áreas para a expansão de graneis líquidos.

Devido à importância do Itaqui do cenário nacional e em função dos desafios a serem superados os gestores e equipe técnica da EMAP, com intuito de garantir que o porto alcance seus objetivos de consolidar-se como o principal porto do Corredor Centro-Norte do país, garantindo excelência logística, competitividade, sustentabilidade e inovação, gerando valor para o Maranhão e toda a sociedade. Além de ser até 2022, a empresa referência em gestão portuária no Brasil decidiram fazer a transição da Norma ISO 9001:2008 para a versão 9001:2015.

Para o desenvolvimento das atividades de implantação da Norma 9001:2015, inicialmente foram identificados e delimitados os 5 (cinco) grupos de processos existentes no Guia PMBOK 2013 5ed (Iniciação, Planejamento, Execução, 
VI CIDESPORT/2019

Congresso Internacional

de Desempenho Portuário

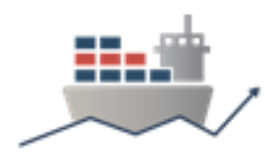

Monitoramento/Controle e Encerramento), que fazem o gerenciamento do ciclo de vida do projeto e de acordo com cada grupo foram elaboradas e realizadas as tarefas necessárias a cada fase da implantação, como apresentado a seguir:

\subsection{Termo de Abertura do Projeto - TAP (Project Charter)}

Nesta fase de iniciação do projeto foi elaborado o Termo de Abertura do Projeto também conhecido como Project Charter. De acordo com SOTILLE (2014) é um documento interno da organização que autoriza formalmente o início de um projeto. O termo de abertura serve também de referencia para a tomada de decisão sobre o prosseguimento do projeto, em particular nos estágios iniciais, pois consolida informações preliminares sob níveis normalmente elevados de incerteza. A seguir são apresentados os itens elaborados para o TAP do estudo:

\subsubsection{Justificativa}

A Empresa Maranhense de Administração Portuária - EMAP administra o Porto do Itaqui, que atualmente figura como um dos principais portos do Norte-Nordeste. E como qualquer empresa nos dias de hoje, tem sentido a influência das transformações globais em sua estrutura organizacional e gestão. Por esta razão, a EMAP tem desenvolvido diferentes estratégias para a atração de novos clientes e investidores, o que faz surgir à oportunidade para a aplicação da metodologia de gestão de projetos em seus processos visando sempre melhorias no nível dos serviços prestados à comunidade portuária. Uma das principais estratégias é o investimento na melhoria de atendimento ao cliente através de um sistema de gestão da qualidade baseado na norma ISO 9001:2015. Para atender a esta demanda, a EMAP está implantando em todos os departamentos da empresa um projeto para implementação da ISO 9001:2015 com foco na satisfação do cliente. Logo, considerando a relevância do escopo deste projeto, fez-se necessário o gerenciamento do escopo através da elaboração do plano de gerenciamento para aumentar consideravelmente, a probabilidade de sucesso do projeto.

\subsubsection{Objetivo do Projeto}

Sistema de Gestão da Qualidade da EMAP orientado e praticado conforme os requisitos da Norma ISO 9001:2015, com a finalidade de prover serviços padronizados que atendam às necessidades dos clientes e aumentem sua satisfação.

\subsubsection{Gerente do Projeto, Responsabilidades e Autoridade}

A Gerente designada para a condução do projeto foi a senhora Ana Carolina Oliveira Maciel, e teve como atribuições as entregas estabelecidas para o projeto, dentro do padrão de qualidade acordado e das premissas e restrições mapeadas. Sua autoridade foi total na esfera do projeto, estando subordinada diretamente ao diretor de planejamento e desenvolvimento da Empresa maranhense de administração portuária - EMAP.

\subsubsection{Metas}


VI CIDESPORT/2019

Congresso Internacional

de Desempenho Portuário

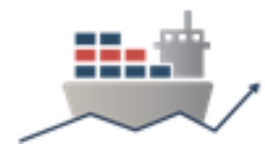

- Adequar a EMAP aos novos requisitos da Norma ISO 9001:2015.

- Certificar a EMAP na Norma ISO 9001:2015.

\subsubsection{Escopo do Projeto}

Princípios da gestão da qualidade aplicados de forma efetiva nas operações da EMAP conforme Norma ISO 9001:2015.

\subsubsection{Orçamento Estimado}

- Gasto de R\$ 6.969,60 com contratação de Consultoria Especializada para apoio e elaboração do Planejamento Estratégico;

- Gasto de R\$10.000,00 com Treinamento externo de interpretação e implementação da Norma ISO 9001:2015 para equipe da Gerência da Qualidade;

- Gasto de R\$14.700,00 com contratação de empresa Certificadora na Norma 9001:2015;

- O projeto foi desenvolvido com equipe própria da EMAP.

\subsubsection{Premissas}

- A equipe da qualidade já possuía experiência, capacidade e habilidade na implementação de ferramentas da qualidade e, portanto, não havia necessidade da contratação de uma consultoria especializada em transição de normas para o suporte a este projeto;

- Na empresa já existia uma cultura da qualidade disseminada.

\subsubsection{Restrições}

- Limitação de tempo, pois a partir do dia 15 de setembro de 2018, o certificado para a Norma ISO 9001:2008 não será mais válido, ou seja, se a empresa não fizer a transição até esta data a EMAP perderá esta certificação.

\subsubsection{Riscos}

- Falha em alguma etapa de implementação do projeto devido à ausência de uma consultoria especializada para apoio a transição das normas o que poderia implicar na não certificação da empresa;

- Mudança no escopo da certificação devido à inclusão de outras unidades de negócio da empresa no projeto;

- Treinamento inadequado;

- Resistência por parte dos colaboradores à nova norma;

- Falta de efetividade nos processos estabelecidos.

\subsubsection{Gerente e Equipe de Projeto}


VI CIDESPORT/2019

Congresso Internacional

de Desempenho Portuário

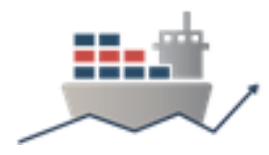

\begin{tabular}{|l|c|c|}
\multicolumn{1}{|c|}{ Nome } & Cargo & E-mail \\
\hline Ana Carolina Maciel & Gerente da Qualidade & ana.maciel@emap.ma.gov.br \\
\hline Keles Regina & $\begin{array}{c}\text { Assessora da } \\
\text { Qualidade IV }\end{array}$ & Keles.regina@emap.ma.gov.br \\
\hline Melissa Faray & $\begin{array}{c}\text { Assessora da } \\
\text { Qualidade III }\end{array}$ & melissa.faray@emap.ma.gov.br \\
\hline Raissa Amaral & $\begin{array}{c}\text { Assessora da } \\
\text { Qualidade II }\end{array}$ & raissa.amarla@emap.ma.gov.br \\
\hline Marroniele Pinheiro & $\begin{array}{c}\text { Assistente da } \\
\text { Qualidade II }\end{array}$ & $\begin{array}{c}\text { Assistente.gequa@emap.ma.gov. } \\
\text { br }\end{array}$ \\
\hline
\end{tabular}

Quadro 1 - Equipe do projeto.

Elaborado pelos autores.

\subsection{Planejar o Gerenciamento do Escopo do Estudo de Caso}

Segundo SOTILLE (2014), um bom plano de gerenciamento de escopo inclui o seguinte conteúdo:

- Roteiro de preparação de uma Declaração detalhada do escopo do projeto;

- Procedimento para a construção da Estrutura Analítica de Projeto (EAP) com as respectivas regras para a sua aprovação e manutenção;

- Regras sobre a aceitação formal das entregas como o uso de um formulário padrão, por exemplo;

- Procedimentos para gerenciamento de mudanças, documentando como elas serão monitoradas.

A seguir são apresentados os itens elaborados para o Plano de Gerenciamento de Escopo feito para o projeto:

\subsubsection{Informações Gerais do Escopo}

- A Baseline de Escopo deste projeto está documentada na Estrutura Analítica de Projeto (EAP) e em seu dicionário. Não deverá ser realizada pela equipe de projeto nenhuma atividade que não esteja definida nesta baseline.

- Este Plano de Gerenciamento apresenta os procedimentos que serão utilizados para definir, verificar e controlar o escopo do projeto, com ênfase em como a estrutura analítica do projeto (EAP) será criada e como serão gerenciadas as alterações no escopo do projeto, ou seja, como as mudanças do escopo serão identificadas, classificadas e, caso autorizadas, integradas ao projeto.

- Para a definição do entendimento padrão do escopo do projeto e de outras informações importantes à sua condução, deverá ser elaborada a Declaração de Escopo que de acordo Vargas (2014) é o documento que formaliza o escopo de todos os trabalhos a serem desenvolvidos no projeto, servindo de base para futuras decisões do projeto. Este documento apresentará os seguintes itens:

- Descrição do Escopo;

- Principais Partes Interessadas;

- Etapas Previstas para o Projeto;

- Critérios de Aceitação; 
VI CIDESPORT/2019

Congresso Internacional

de Desempenho Portuário

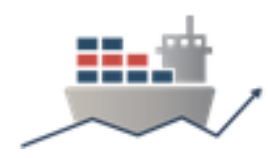

- Metodologia;

- Equipe do Projeto;

- Escopo Não Incluído no Projeto;

- Ligações com Outros Projetos.

- A partir da Declaração de Escopo do Projeto deve ser elaborada a EAP, que deve ser criada através da técnica top-down os seguintes passos devem ser seguidos:

1. Colocar no primeiro nível o nome do projeto;

2. Colocar no segundo nível as fases do ciclo de vida do projeto (produtos), acrescido de um item para o gerenciamento do projeto;

3. Identificar os subprodutos (entregas) de cada fase do projeto;

4. Verificar se o planejamento de custo e tempo, assim como a identificação de riscos e atribuição de responsabilidades, podem ser desenvolvidas neste nível de detalhe.

\subsubsection{Coletar Requisitos}

- O Presidente da empresa espera a Implantação da nova Norma ISO 9001:2015 em 10 meses;

- O Diretor de Planejamento (Sponsor) solicita que o projeto não gaste mais que $\mathrm{R} \$ 31.699,90$ do orçamento anual da Gerência da Qualidade;

- A gerente de Projeto deseja que a Diretoria de Operações de adeque aos novos requisitos da Norma ISO 9001:2015 após os 10 meses;

- A Gerente de Projeto espera que a Equipe da Gerência da Qualidade seja treinada na Norma ISO 9001:2015;

- A Gerente de Projeto espera que a Liderança da Diretoria de Operações seja treinada nos requisitos da Norma ISO 9001:2015;

- A Gerente de Projeto espera que seja realizada uma Auditoria Interna;

- A Gerente de Projeto espera que seja realizada uma Auditoria Externa.

\subsubsection{Definir o Escopo}

- Os Princípios da Gestão da Qualidade devem ser aplicados de forma efetiva na Diretoria de Operações da EMAP conforme Norma ISO 9001:2015. Para isto serão executados os seguintes passos:

1 - Planejamento das atividades do projeto,

2 - Um treinamento externo de interpretação e implementação da Norma ISO 9001:2015 será solicitado a para equipe da Gerência da Qualidade;

3 - Será ministrado um treinamento interno para a liderança da Diretoria de Operações sobre os requisitos da Norma ISO 9001:2015;

4 - Um Diagnóstico para verificação da aderência da empresa aos novos requisitos da Norma 9001:2015 terá que ser realizado;

5 - Elaboração do desenvolvimento e execução do Projeto.

\subsubsection{Criar Estrutura Analítica de Projeto (EAP)}

A Figura 03 abaixo apresenta a EAP criada para a execução do projeto, à qual será apresentada detalhadamente no decorrer do desenvolvimento do estudo. 
VI CIDESPORT/2019

Congresso Internacional

de Desempenho Portuário
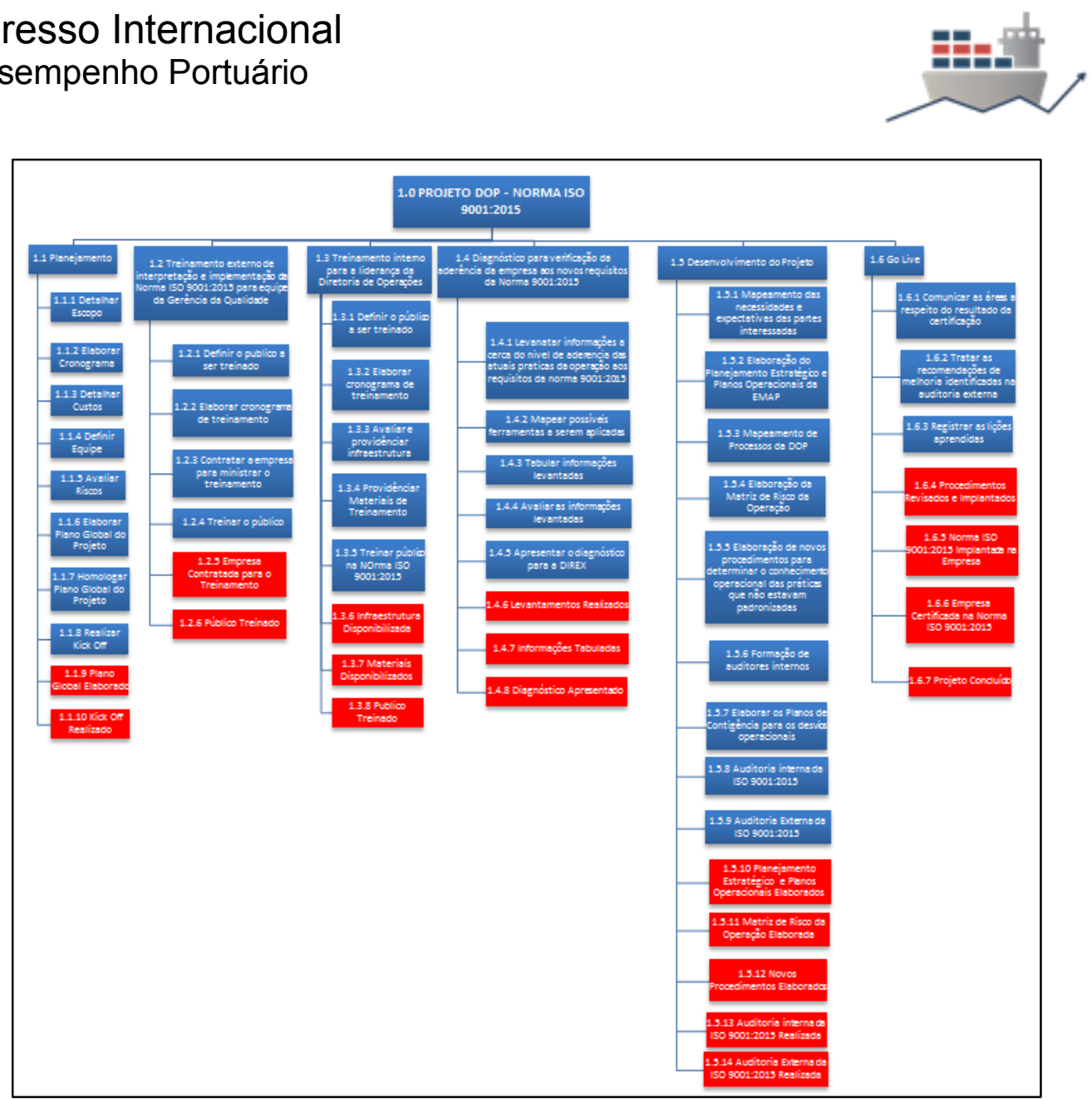

Figura 03 - EAP criada para o Projeto.

Elaborado pelos autores.

\subsubsection{Verificar Escopo}

- É importante lembrar que a verificação do escopo é o processo de obter o aceite formal do escopo do projeto pelas partes envolvidas. Quando houver a finalização de um deliverable do projeto, o gerente do projeto, ou alguém por ele designado, deverá fazer uma inspeção, junto com o stakeholder responsável pela aceitação, do produto ou serviço gerado. A inspeção poderá incluir atividades tais como medição, exames e testes incumbidos de determinar se os resultados estão de acordo com as exigências, conforme estabelecido nos critérios de aceitação para o deliverable em questão.

\subsubsection{Controle de Escopo}

- Quando alguma necessidade de mudança de escopo for identificada, deve ser gerada uma Solicitação de Mudança de Escopo (SME), a qual poderá ser solicitada por qualquer um dos membros da equipe. Este pedido será analisado pelo gerente do projeto, que avaliará os impactos da mesma no projeto e a registrará no espaço destinado a este fim. O gerente do projeto poderá autorizar alterações de escopo que não tenham impacto no custo e no prazo total do projeto, assim como na qualidade do produto, se for o caso. Caso contrário, após o registro desse impacto na SME, o gerente deve enviá-la para aprovação ou não pela Diretoria Executiva. 
VI CIDESPORT/2019

Congresso Internacional

de Desempenho Portuário

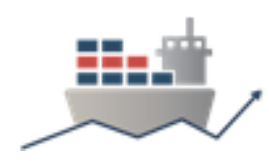

\section{COLETAR REQUISITOS DO ESTUDO DE CASO}

Conforme SOTILLE (2014), requisitos são um vetor crítico para a construção da EAP, bem como para as estimativas de prazo e custo, além do planejamento da qualidade $\mathrm{e}$, frequentemente das aquisições. A coleta dos requisitos do projeto apresentado neste estudo foi realizada através de entrevistas e brainstormings feitas em reuniões com os funcionários que atuam nos diferentes setores da diretoria envolvida no projeto como por exemplo, planejamento, operação, controle e logística, para entender melhor como trabalhar as expectativas das partes envolvidas no projeto. A Figura 04 apresenta a matriz de rastreabilidade de requisitos, que foi resultado da coleta e que se transformou também em um documento do projeto.

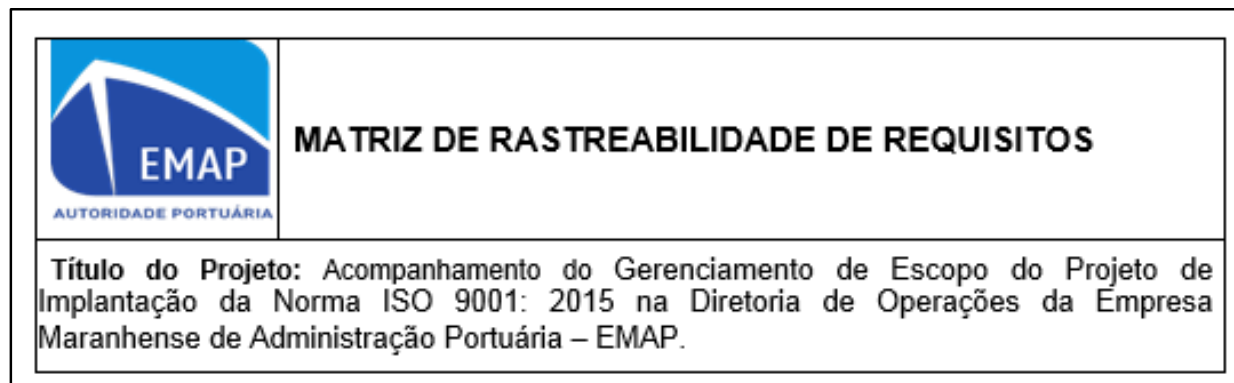

\begin{tabular}{|c|c|c|c|c|c|}
\hline \multicolumn{6}{|c|}{ REQUISITOS DO PROJETO } \\
\hline Item & Descrição & Solicitante & Fonte & Prioridade & $\begin{array}{l}\text { Data de } \\
\text { Inclusão }\end{array}$ \\
\hline 01 & $\begin{array}{l}\text { - Implantação da nova Norma ISO } \\
\text { 9001:2015 em } 10 \text { meses. }\end{array}$ & $\begin{array}{l}\text { Presidente } \\
\text { da EMAP }\end{array}$ & DIREX & Alta & $2^{\circ}$ Trimestre \\
\hline 02 & $\begin{array}{l}\text { - Não gastar do orçamento anual } \\
\text { da Gerência mais de RS } \\
31.699,90 \text {. }\end{array}$ & Sponsor & TAP & Alta & $2^{\circ}$ Trimestre \\
\hline 03 & $\begin{array}{l}\text { - Diretoria de Operação adequada } \\
\text { aos novos requisitos da Norma } \\
\text { ISO } 9001: 2015 \text { após os } 10 \text { meses. }\end{array}$ & $\begin{array}{c}\text { Gerente do } \\
\text { Projeto }\end{array}$ & TAP & Alta & $2^{\circ}$ Trimestre \\
\hline 04 & $\begin{array}{l}\text { - Equipe da Gerência da Qualidade } \\
\text { treinada na Norma ISO 9001:2015. }\end{array}$ & $\begin{array}{c}\text { Gerente do } \\
\text { Projeto }\end{array}$ & $\begin{array}{r}\text { Declaração } \\
\text { de Escopo }\end{array}$ & Média & $2^{\circ}$ Trimestre \\
\hline 05 & $\begin{array}{l}\text { Liderança da Diretoria de } \\
\text { Operações treinada nos requisitos } \\
\text { da Norma ISO 9001:2015. }\end{array}$ & $\begin{array}{l}\text { Gerente do } \\
\text { Projeto }\end{array}$ & $\begin{array}{r}\text { Declaração } \\
\text { de Escopo }\end{array}$ & Média & $2^{\circ}$ Trimestre \\
\hline 06 & - Realização de Auditoria Interna. & $\begin{array}{l}\text { Gerente do } \\
\text { Projeto }\end{array}$ & $\begin{aligned} \text { Declaração } \\
\text { de Escopo }\end{aligned}$ & Média & $2^{\circ}$ Trimestre \\
\hline 07 & - Realização de Auditoria Externa. & $\begin{array}{c}\text { Gerente do } \\
\text { Projeto }\end{array}$ & $\begin{aligned} \text { Declaração } \\
\text { de Escopo }\end{aligned}$ & Média & $2^{\circ}$ Trimestre \\
\hline & & & & & \\
\hline & & & & & \\
\hline & & & & & \\
\hline $\begin{array}{l}\text { Gerent } \\
\text { Ana Ca }\end{array}$ & $\begin{array}{l}\text { do Projeto: } \\
\text { rolina Oliveira Maciel }\end{array}$ & & Data: & & \\
\hline
\end{tabular}

Figura 04 - Matriz de Rastreabilidade de Requisitos do Projeto.

Elaborado pelos autores.

\section{DEFINIR O ESCOPO DO ESTUDO DE CASO}




\section{CIDESPORT/2019}

\section{Congresso Internacional}

de Desempenho Portuário

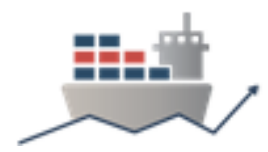

Definir o escopo consiste em desenvolver descrição detalhada do projeto e do produto que servirá como base para futuras decisões. A preparação detalhada da declaração do escopo é crítica para o sucesso do projeto e baseia-se nas entregas principais, premissas e restrições que são documentadas durante a iniciação do projeto. Neste momento surge a necessidade da elaboração da Declaração de Escopo, que neste caso tem como função detalhar as informações preliminares apresentadas no Termo de Abertura do Projeto. A seguir são apresentados os itens elaborados para a Declaração de Escopo do Projeto.

\subsection{Descrição Geral do Escopo}

- O projeto deve capacitar e implementar na Diretoria de Operações nos requisitos da Norma 9001:2015 para garantir serviços padronizados que atendam às necessidades dos clientes e aumente o nível de satisfação dos mesmos.

\subsection{Principais Partes Interessadas}

- O Presidente da Empresa

- Diretor de Planejamento e Desenvolvimento

- Diretoria de Operações

- Operadores Portuários

- Clientes

- Órgãos Anuentes

\subsection{Etapas Previstas}

\begin{tabular}{|c|c|c|c|}
\hline \multicolumn{2}{|c|}{ ETAPAS } & Critério de Aceitação & Durações \\
\hline 1 & - Planejamento; & $\begin{array}{l}\text { - Avaliação e aprovação } \\
\text { da Diretoria Executiva. }\end{array}$ & 10 dias \\
\hline 2 & $\begin{array}{l}\text { - Treinamento externo de interpretação e } \\
\text { implementação da Norma ISO 9001:2015 para } \\
\text { equipe da Gerência da Qualidade; }\end{array}$ & $\begin{array}{l}\text { - Avaliação e aprovação } \\
\text { da Gerente de Projeto. }\end{array}$ & 6 dias \\
\hline 3 & $\begin{array}{l}\text { - Treinamento interno para a liderança da Diretoria } \\
\text { de Operações; }\end{array}$ & $\begin{array}{l}\text { - Avaliação e aprovação } \\
\text { da Gerente de Projeto. }\end{array}$ & 2 dias \\
\hline 4 & $\begin{array}{l}\text { - Diagnóstico para verificação da aderência da } \\
\text { empresa aos novos requisitos da norma } \\
\text { 9001:2015; }\end{array}$ & $\begin{array}{l}\text { - Avaliação e aprovação } \\
\text { da Gerente de Projeto. }\end{array}$ & 20 dias \\
\hline 5 & - Desenvolvimento do Projeto; & $\begin{array}{l}\text { - Avaliação e aprovação } \\
\text { da Diretoria Executiva. }\end{array}$ & 180 dias \\
\hline 6 & - Go live. & $\begin{array}{l}\text { - Avaliação e aprovação } \\
\text { da Gerente de Projeto. }\end{array}$ & 5 dias \\
\hline
\end{tabular}

Quadro 2 - Etapas elaboradas para o projeto.

\subsection{Metodologia}




\section{CIDESPORT/2019}

\section{Congresso Internacional}

de Desempenho Portuário

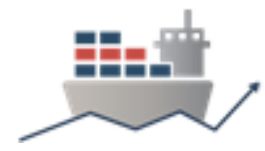

- A metodologia utilizada tem uma abordagem descritiva e aplicativa, conta com uma pesquisa bibliográfica e estudo de caso participante relacionado ao tema gerenciamento de projetos, em específico a parte de escopo com a finalidade de demonstrar e instruir a aplicação das boas práticas do gerenciamento de projeto descritas no Guia PMBOK 2013 5ed, na implantação da Norma 9001:2015 em uma empresa pública do setor portuário.

\subsection{Equipe Responsável}

\begin{tabular}{|l|c|c|}
\hline \multicolumn{1}{|c|}{ Membro } & Cargo & Função \\
\hline - Jailson Luz & $\begin{array}{c}\text { Diretor Planejamento e de Trabalho } \\
\text { Desenvolvimento }\end{array}$ & Sponsor \\
\hline - Ana Carolina Maciel & Gerente da Qualidade & Gerente de Projeto \\
\hline - Keles Regina & Assessora da Qualidade IV & Apoio à Implementação \\
\hline Melissa Faray & Assessora da Qualidade III & Apoio à Implementação \\
\hline - Raissa Amaral & Assessora da Qualidade II & Apoio à Implementação \\
\hline - Marroniele Pinheiro & Assistente da Qualidade II & Apoio à Implementação \\
\hline
\end{tabular}

Quadro 3 - Descrição das reponsabilidades da equipe do projeto.

Elaborado pelos autores.

\subsection{Escopo Não Incluído no Projeto}

- Não está incluído neste projeto as atividades desenvolvidas nas áreas de apoio da Emap, tais como Recursos Humanos, Engenharia, Compras e Contratos, TI, Área Patrimonial, Área de Manutenção e Terminais de Passageiros.

\subsection{Ligações com Outros Projetos}

- Este projeto não sofre a interferência de outros projetos;

- Este projeto será a base para a certificação da ISO 14001:2015 referente ao sistema de gestão ambiental e ISO 45001 referente ao sistema de saúde e segurança do trabalho. 
VI CIDESPORT/2019

Congresso Internacional

de Desempenho Portuário

\subsection{Registro de Revisões}

\section{REGISTRO DE REVISÕES}

\begin{tabular}{|c|c|c|c|c|}
\hline Revisão & Data & Descrição da Mudança & Revisão & Aprovação \\
\hline & -1 & $\begin{array}{l}\text { [Registrar resumidamente as mudanças } \\
\text { ocorridas. Mencionar item e página que houve a } \\
\text { alteração]. }\end{array}$ & $\begin{array}{l}\text { [Nome do } \\
\text { responsável } \\
\text { pela revisão] }\end{array}$ & $\begin{array}{l}\text { [Nome do } \\
\text { responsável } \\
\text { pela } \\
\text { aprovação] }\end{array}$ \\
\hline & 一1 & & & \\
\hline & II & & & \\
\hline & II & & & \\
\hline & -1 & & & \\
\hline & rojeto: & na Carolina Oliveira Maciel & \multicolumn{2}{|c|}{ Data: } \\
\hline
\end{tabular}

Quadro 4 - Documento de registro de revisões do projeto.

Elaborado pelos autores.

\section{CRIAR A ESTRUTURA ANALÍTICA DO PROJETO DO ESTUDO DE CASO}

Nesta etapa conforme descrito anteriormente, o projeto deve ser subdivido em partes menores para facilitar o seu gerenciamento. A decomposição hierárquica do escopo deve ser respeitada e a EAP organizará e definirá o escopo total do projeto, representando o trabalho especificado na declaração do escopo do projeto aprovada pela equipe. A Figura 05 mostra a Estrutura Analítica de Projeto elaborada para o estudo de caso e o Dicionário da EAP pode ser visto logo depois na Tabela 01. 
VI CIDESPORT/2019

Congresso Internacional de Desempenho Portuário
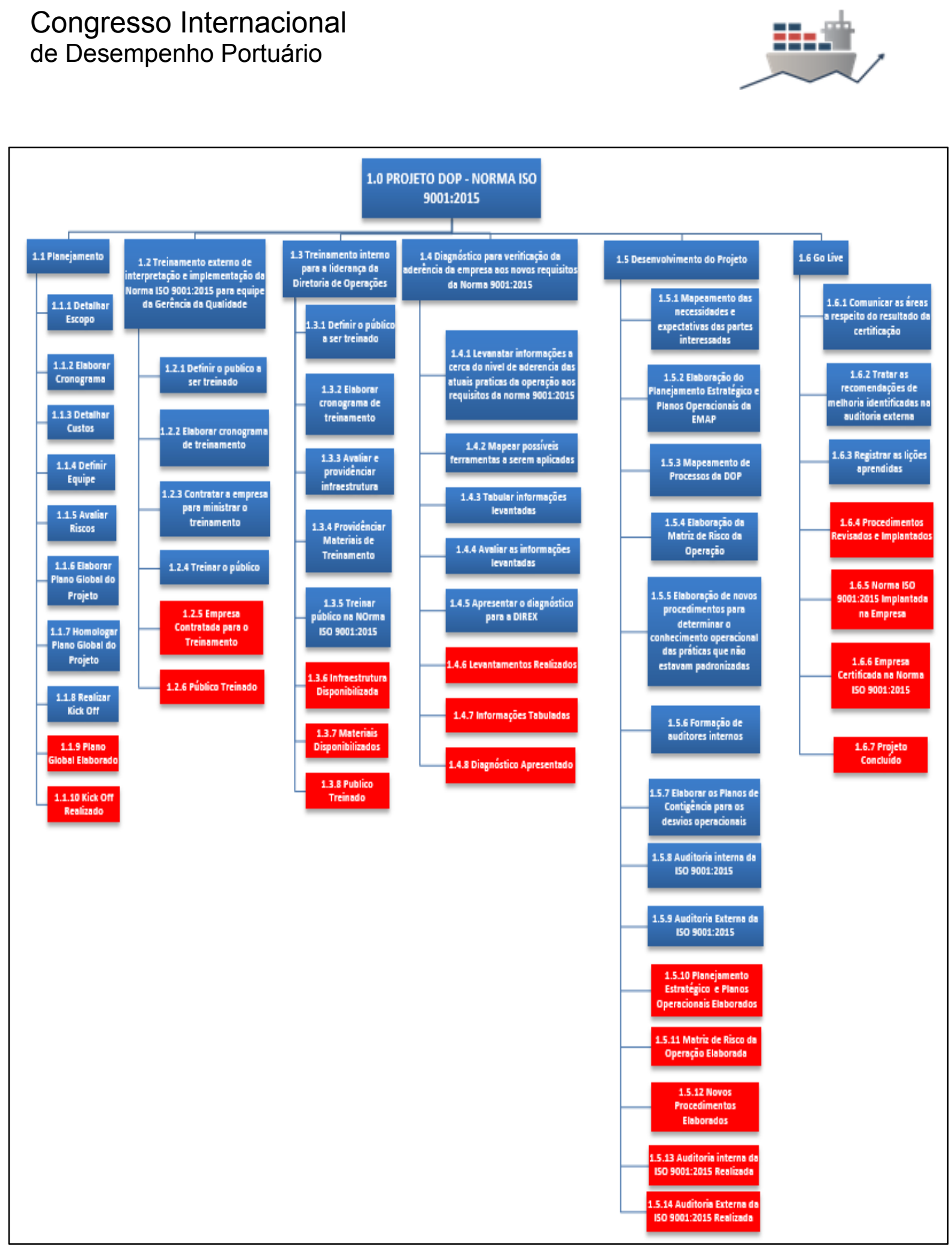

Figura 05 - Estrutura Analítica do Projeto.

Elaborado pelos autores.

Tabela 01 - Dicionário da EAP 
VI CIDESPORT/2019

Congresso Internacional

de Desempenho Portuário

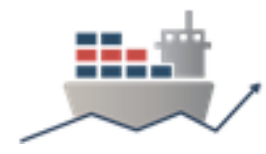

\begin{tabular}{|c|c|c|c|}
\hline EMAP & \multicolumn{3}{|c|}{$\begin{array}{l}\text { DICIONÁRIO DA ESTRUTURA ANALÍTICA DE PROJETO } \\
\text { (EAP) }\end{array}$} \\
\hline ID NA EAP & PACOTE DE TRABALHO & $\begin{array}{c}\text { ESPECIFICAÇÃO DA } \\
\text { ENTREGA }\end{array}$ & $\begin{array}{l}\text { CRITÉRIO DE } \\
\text { ACEITAÇÃO }\end{array}$ \\
\hline 1.1.1 & - Detalhar Escopo & $\begin{array}{l}\text { - Informar as atividades que } \\
\text { deverão ser desenvolvidas para a } \\
\text { execução do projeto e o que não } \\
\text { entrará no escopo do trabalho. }\end{array}$ & $\begin{array}{l}\text { - Ser aprovado pela } \\
\text { Gerente de Projeto. }\end{array}$ \\
\hline 1.1 .2 & - Elaborar Cronograma & $\begin{array}{l}\text { - Apresentar cronograma com } \\
\text { marcos de controle e com o } \\
\text { caminho crítico sinalizado para o } \\
\text { projeto. }\end{array}$ & $\begin{array}{l}\text { - Ser aprovado pelo } \\
\text { Sponsor. }\end{array}$ \\
\hline 1.1 .3 & - Detalhar Custos & $\begin{array}{l}\text { Apresentar os valores } \\
\text { detalhados que serão gastos em } \\
\text { cada etapa do projeto. }\end{array}$ & $\begin{array}{l}\text { - Ser aprovado pelo } \\
\text { Sponsor. }\end{array}$ \\
\hline 1.1 .4 & - Definir Equipe & $\begin{array}{l}\text { - Apresentar a lista com os } \\
\text { integrantes da equipe de projeto } \\
\text { descrevendo cargo e função de } \\
\text { cada membro. }\end{array}$ & $\begin{array}{l}\text { - Ser aprovado pela } \\
\text { Gerente de Projeto. }\end{array}$ \\
\hline 1.1 .5 & - Avaliar Riscos & $\begin{array}{l}\text { - Fazer um levantamento dos } \\
\text { possíveis riscos a que projeto } \\
\text { estará exposto. }\end{array}$ & $\begin{array}{l}\text { - Ser aprovado pela } \\
\text { Gerente de Projeto. }\end{array}$ \\
\hline 1.1 .6 & $\begin{array}{l}\text { - Elaborar Plano Global do } \\
\text { Projeto }\end{array}$ & $\begin{array}{l}\text { - Criar um Plano de } \\
\text { Gerenciamento do Projeto que } \\
\text { comtemple todas as atividades } \\
\text { que serão realizadas ao longo do } \\
\text { projeto. }\end{array}$ & $\begin{array}{l}\text { - Ser aprovado pela } \\
\text { Gerente de Projeto. }\end{array}$ \\
\hline 1.1 .7 & $\begin{array}{l}\text { - Homologar Plano Global } \\
\text { do Projeto }\end{array}$ & $\begin{array}{lllr}\text { - Apresentar } & \text { o } & \text { Plano } & \text { de } \\
\text { Gerenciamento do } & \text { Projeto } & \text { ao } \\
\text { sponsor e presidente da empresa. }\end{array}$ & $\begin{array}{l}\text { - Ser aprovado pela } \\
\text { Diretoria Executiva. }\end{array}$ \\
\hline 1.1 .8 & - Realizar Kick Off & $\begin{array}{l}\text { - Realizar a reunião de abertura } \\
\text { oficial do projeto. }\end{array}$ & $\begin{array}{l}\text { - Ser aprovado pela } \\
\text { Gerente de Projeto. }\end{array}$ \\
\hline 1.1 .9 & - Plano Global Elaborado & $\begin{array}{l}\text { - Marco formal de entrega do } \\
\text { Plano Global. }\end{array}$ & $\begin{array}{l}\text { - Ser aprovado pela } \\
\text { Gerente de Projeto. }\end{array}$ \\
\hline 1.1 .10 & - Kick Off Realizado & $\begin{array}{l}\text { - Marco formal de realização da } \\
\text { reunião de Kick Off. }\end{array}$ & $\begin{array}{l}\text { - Ser aprovado pela } \\
\text { Gerente de Projeto. }\end{array}$ \\
\hline 1.2 .1 & $\begin{array}{l}\text {-Definir o público a ser } \\
\text { treinado }\end{array}$ & $\begin{array}{l}\text { - Treinar toda a equipe da } \\
\text { Qualidade. }\end{array}$ & $\begin{array}{l}\text { - Ser aprovado com } \\
\text { no mínimo nota } 7,0 \\
\text { no teste do curso } \\
\text { ministrado. }\end{array}$ \\
\hline 1.2 .2 & $\begin{array}{l}\text { - Elaborar cronograma de } \\
\text { treinamento }\end{array}$ & $\begin{array}{l}\text { - Apresentar cronograma com } \\
\text { marcos de controle. }\end{array}$ & \begin{tabular}{|l|} 
- Ser aprovado pela \\
Gerente de Projeto.
\end{tabular} \\
\hline 1.2 .3 & $\begin{array}{l}\text { - Contratar a empresa para } \\
\text { ministrar o treinamento }\end{array}$ & $\begin{array}{l}\text { - Garantir as inscrições da equipe } \\
\text { técnica da qualidade no } \\
\text { treinamento da ISO } 9001: 2015 .\end{array}$ & $\begin{array}{l}\text { - A empresa deve } \\
\text { ser bem } \\
\text { conceituada no } \\
\text { mercado. }\end{array}$ \\
\hline 1.2 .4 & - Treinar o público & $\begin{array}{l}\text { - Capacitar os treinandos na } \\
\text { Norma ISO 9001:2015. }\end{array}$ & $\begin{array}{l}\text { - Colaboradores } \\
\text { capacitados para } \\
\text { desenvolver suas } \\
\text { atividades. }\end{array}$ \\
\hline 1.2 .5 & $\begin{array}{l}\text { - Empresa Contratada para } \\
\text { o Treinamento }\end{array}$ & $\begin{array}{l}\text { - Marco formal de contratação da } \\
\text { empresa. }\end{array}$ & $\begin{array}{l}\text { - Ser aprovado pela } \\
\text { Gerente de Projeto. }\end{array}$ \\
\hline
\end{tabular}


VI CIDESPORT/2019

Congresso Internacional

de Desempenho Portuário

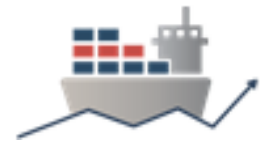

\begin{tabular}{|c|c|c|c|}
\hline 1.2 .6 & - Público Treinado & $\begin{array}{l}\text { - Marco formal de conclusão do } \\
\text { treinamento. }\end{array}$ & $\begin{array}{l}\text { - Ser aprovado pela } \\
\text { Gerente de Projeto. }\end{array}$ \\
\hline 1.3 .1 & $\begin{array}{l}\text { - Definir o público a ser } \\
\text { treinado }\end{array}$ & $\begin{array}{l}\text { - Treinar toda a liderança da } \\
\text { Diretoria de Operações. }\end{array}$ & $\begin{array}{l}\text { - Ser aprovado com } \\
\text { no mínimo nota } 7,0 \\
\text { no teste do curso } \\
\text { ministrado. }\end{array}$ \\
\hline 1.3 .2 & $\begin{array}{l}\text { - Elaborar cronograma de } \\
\text { treinamento }\end{array}$ & $\begin{array}{l}\text { - Apresentar cronograma com } \\
\text { marcos de controle. }\end{array}$ & $\begin{array}{l}\text { - Ser aprovado pela } \\
\text { Gerente de Projeto. }\end{array}$ \\
\hline 1.3 .3 & $\begin{array}{l}\text { - Avaliar e providenciar } \\
\text { infraestrutura }\end{array}$ & $\begin{array}{l}\text { - Reservar as salas } \\
\text { equipamentos necessários. }\end{array}$ & $\begin{array}{l}\text { - Disponíveis e } \\
\text { adequados para o } \\
\text { uso. }\end{array}$ \\
\hline 1.3 .4 & $\begin{array}{l}\text { - Providenciar Materiais de } \\
\text { Treinamento }\end{array}$ & - Elaborar a apresentação. & $\begin{array}{l}\text { - Ser aprovado pela } \\
\text { Gerente de Projeto. }\end{array}$ \\
\hline 1.3 .5 & $\begin{array}{l}\text { - Treinar público na Norma } \\
\text { ISO 9001:2015 }\end{array}$ & $\begin{array}{l}\text { - Capacitar os treinandos na } \\
\text { Norma ISO 9001:2015. }\end{array}$ & $\begin{array}{l}\text { - Colaboradores } \\
\text { capacitados para } \\
\text { desenvolver suas } \\
\text { atividades. }\end{array}$ \\
\hline 1.3 .6 & $\begin{array}{l}\text { - Infraestrutura } \\
\text { Disponibilizada }\end{array}$ & $\begin{array}{l}\text { - Marco formal de aceitação da } \\
\text { infraestrutura. }\end{array}$ & $\begin{array}{l}\text { - Ser aprovado pela } \\
\text { Gerente de Projeto. }\end{array}$ \\
\hline 1.3 .7 & - Materiais Disponibilizados & $\begin{array}{l}\text { - Marco formal de aceitação do } \\
\text { material para o curso. }\end{array}$ & $\begin{array}{l}\text { - Ser aprovado pela } \\
\text { Gerente de Projeto. }\end{array}$ \\
\hline 1.3 .8 & - Público Treinado & $\begin{array}{l}\text { - Marco formal de conclusão do } \\
\text { treinamento. }\end{array}$ & $\begin{array}{l}\text { - Ser aprovado pela } \\
\text { Gerente de Projeto. }\end{array}$ \\
\hline 1.4 .1 & 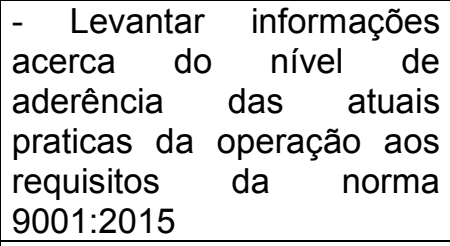 & $\begin{array}{l}\text { - Verificar a aplicação dos } \\
\text { requisitos da Norma 9001:2015 } \\
\text { nos processos atuais. }\end{array}$ & $\begin{array}{l}\text { - Ser aprovado pela } \\
\text { Diretoria Executiva. }\end{array}$ \\
\hline 1.4 .2 & $\begin{array}{llr}\text { - Mapear } & & \text { possíveis } \\
\text { ferramentas } & \text { a } & \text { serem } \\
\text { aplicadas } & & \\
\end{array}$ & $\begin{array}{lcr}\text { - } & \text { Verificar } & \text { ferramentas } \\
\text { qualidade } & \text { necessárias } & \text { à } \\
\text { adaptação da empresa à Norma. }\end{array}$ & $\begin{array}{l}\text { - Ser aprovado pela } \\
\text { Gerente de Projeto. }\end{array}$ \\
\hline 1.4 .3 & $\begin{array}{l}\text { - Tabular informações } \\
\text { levantadas }\end{array}$ & $\begin{array}{l}\text { - Elaborar planilhas com as } \\
\text { informações coletadas. }\end{array}$ & $\begin{array}{l}\text { - Ser aprovado pela } \\
\text { Gerente de Projeto. }\end{array}$ \\
\hline 1.4 .4 & $\begin{array}{ccc}- & \text { Avaliar } & \text { as } \\
\text { informações levantadas } & \end{array}$ & $\begin{array}{l}\text { - Analisar criticamente as } \\
\text { informações obtidas. }\end{array}$ & $\begin{array}{l}\text { - Ser aprovado pela } \\
\text { Gerente de Projeto. }\end{array}$ \\
\hline 1.4 .5 & $\begin{array}{l}\text { - Apresentar o diagnóstico } \\
\text { para a DIREX }\end{array}$ & $\begin{array}{l}\text { - Preparar um relatório do } \\
\text { resultado do diagnóstico. }\end{array}$ & $\begin{array}{l}\text { - Ser aprovado pela } \\
\text { Diretoria Executiva. }\end{array}$ \\
\hline 1.4 .6 & $\begin{array}{ll}\text { - } & \text { Levantamentos } \\
\text { Realizados }\end{array}$ & $\begin{array}{l}\text { - Marco formal de entrega dos } \\
\text { levantamentos. }\end{array}$ & $\begin{array}{l}\text { - Ser aprovado pela } \\
\text { Gerente de Projeto. }\end{array}$ \\
\hline 1.4 .7 & - Informações Tabuladas & $\begin{array}{l}\text { - Marco formal de entrega das } \\
\text { informações tabuladas. }\end{array}$ & $\begin{array}{l}\text { - Ser aprovado pela } \\
\text { Gerente de Projeto. }\end{array}$ \\
\hline 1.4 .8 & - Diagnóstico Apresentado & $\begin{array}{l}\text { - Marco formal da apresentação } \\
\text { do diagnóstico. }\end{array}$ & $\begin{array}{l}\text { - Ser aprovado pela } \\
\text { Gerente de Projeto. }\end{array}$ \\
\hline 1.5 .1 & 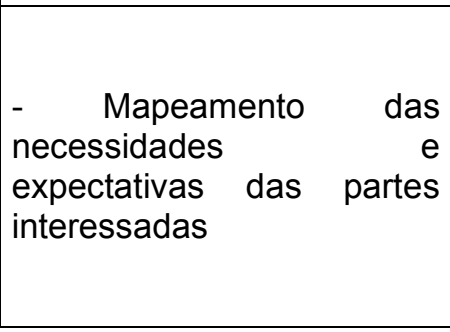 & $\begin{array}{l}\text { - Elaborar documento de } \\
\text { Mapeamento das necessidades e } \\
\text { expectativas das partes } \\
\text { interessadas clientes, OGMO, } \\
\text { Receita federal, ANTAQ, } \\
\text { Comunidade do entorno do porto, } \\
\text { contratadas e Diretoria de } \\
\text { Operações. }\end{array}$ & $\begin{array}{l}\text { - Ser aprovado pela } \\
\text { Diretoria Executiva. }\end{array}$ \\
\hline
\end{tabular}


VI CIDESPORT/2019

Congresso Internacional

de Desempenho Portuário

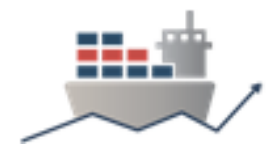

\begin{tabular}{|c|c|c|c|}
\hline 1.5 .2 & $\begin{array}{l}\text { Elaboração do } \\
\text { Planejamento Estratégico e } \\
\text { Planos Operacionais da } \\
\text { EMAP }\end{array}$ & $\begin{array}{l}\text {-Definir o contexto interno e } \\
\text { externo da organização e SWOT } \\
\text { da DOP. }\end{array}$ & $\begin{array}{l}\text { - Ser aprovado pela } \\
\text { Diretoria Executiva. }\end{array}$ \\
\hline 1.5 .3 & $\begin{array}{l}\text { Mapeamento de } \\
\text { Processos da DOP }\end{array}$ & $\begin{array}{l}\text { - Mapeamento dos seguintes } \\
\text { processos da operação: Acesso } \\
\text { Aquaviário, Programação e } \\
\text { Controle } \\
\begin{array}{l}\text { Planejamento Operacional, } \\
\text { Operacional. }\end{array}\end{array}$ & $\begin{array}{l}\text { - Ser aprovado pela } \\
\text { Gerente de Projeto. }\end{array}$ \\
\hline 1.5 .4 & $\begin{array}{l}\text { - Elaboração da Matriz de } \\
\text { Risco da Operação }\end{array}$ & $\begin{array}{l}\text { - Definir os possíveis desvios } \\
\text { operacionais que possam } \\
\text { impactar nos resultados da } \\
\text { operação. }\end{array}$ & $\begin{array}{l}\text { - Ser aprovado pela } \\
\text { Gerente de Projeto. }\end{array}$ \\
\hline 1.5 .5 & $\begin{array}{lr}\text { - Elaboração de } & \text { novos } \\
\text { procedimentos } & \text { para } \\
\text { determinar o conhecimento } \\
\text { operacional das } \\
\text { que práticas } \\
\text { padronizadas } & \\
\end{array}$ & $\begin{array}{l}\text { - Definir práticas padrão para a } \\
\text { estabilidade das operações. }\end{array}$ & $\begin{array}{l}\text { - Ser aprovação } \\
\text { pelo Diretor de } \\
\text { Operações. }\end{array}$ \\
\hline 1.5 .6 & $\begin{array}{l}\text { - Formação de auditores } \\
\text { internos }\end{array}$ & $\begin{array}{l}\text { - Capacitar através de } \\
\text { treinamento colaboradores da } \\
\text { empresa para conduzir auditorias } \\
\text { internas. }\end{array}$ & $\begin{array}{l}\text { - Ser aprovado pela } \\
\text { Gerente de Projeto. }\end{array}$ \\
\hline 1.5 .7 & $\begin{array}{l}\text { - Elaborar os Planos de } \\
\text { Contingência para os } \\
\text { desvios operacionais }\end{array}$ & $\begin{array}{l}\text { - Elaborar cadeias de ajuda para } \\
\text { os principais desvios } \\
\text { operacionais, especificando para } \\
\text { o tratamento dos desvios os } \\
\text { responsáveis envolvidos na } \\
\text { solução do problema, os tempos } \\
\text { estimados e detalhamento das } \\
\text { etapas das ações para solução do } \\
\text { desvio. }\end{array}$ & $\begin{array}{l}\text { - Ser aprovação } \\
\text { pelo Diretor de } \\
\text { Operações. }\end{array}$ \\
\hline 1.5 .8 & $\begin{array}{l}\text { - Auditoria interna da ISO } \\
\text { 9001:2015 }\end{array}$ & $\begin{array}{l}\text { - Verificar a aderência da DOP } \\
\text { aos requisitos da Norma. }\end{array}$ & $\begin{array}{l}\text { - Ser aprovado pela } \\
\text { Gerente de Projeto. }\end{array}$ \\
\hline 1.5 .9 & $\begin{array}{l}\text { - Auditoria Externa da ISO } \\
\text { 9001:2015 }\end{array}$ & $\begin{array}{l}\text { - Verificar a aderência da DOP } \\
\text { aos requisitos da Norma. }\end{array}$ & $\begin{array}{l}\text { - Ser aprovado pela } \\
\text { Empresa } \\
\text { certificadora. }\end{array}$ \\
\hline 1.5 .10 & $\begin{array}{l}\text { - Planejamento Estratégico } \\
\text { e Planos Operacionais } \\
\text { Elaborados }\end{array}$ & $\begin{array}{l}\text { - Marco formal da entrega do } \\
\text { Planejamento Estratégico e } \\
\text { Planos Operacionais. }\end{array}$ & $\begin{array}{l}\text { - Ser aprovado pela } \\
\text { Gerente de Projeto. }\end{array}$ \\
\hline 1.5 .11 & $\begin{array}{l}\text { Matriz de Risco da } \\
\text { Operação Elaborada }\end{array}$ & $\begin{array}{l}\text { - Marco formal da entrega da } \\
\text { Matriz de Risco da Operação. }\end{array}$ & $\begin{array}{l}\text { - Ser aprovado pela } \\
\text { Gerente de Projeto. }\end{array}$ \\
\hline 1.5 .12 & 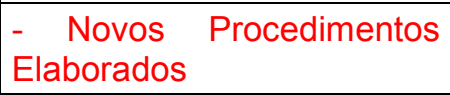 & $\begin{array}{l}\text { - Marco formal da entrega dos } \\
\text { novos procedimentos. }\end{array}$ & $\begin{array}{l}\text { - Ser aprovado pela } \\
\text { Gerente de Projeto. }\end{array}$ \\
\hline 1.5 .13 & $\begin{array}{l}\text { - Auditoria interna da ISO } \\
\text { 9001:2015 Realizada }\end{array}$ & $\begin{array}{l}\text { - Marco formal da finalização da } \\
\text { Auditoria Interna. }\end{array}$ & $\begin{array}{l}\text { - Ser aprovado pela } \\
\text { Gerente de Projeto. }\end{array}$ \\
\hline 1.5 .14 & $\begin{array}{l}\text { - Auditoria Externa da ISO } \\
\text { 9001:2015 Realizada }\end{array}$ & $\begin{array}{l}\text { - Marco formal da finalização da } \\
\text { Auditoria Externa. }\end{array}$ & $\begin{array}{l}\text { - Ser aprovado pela } \\
\text { Gerente de Projeto. }\end{array}$ \\
\hline 1.6 .1 & $\begin{array}{l}\text { - Comunicar as áreas a } \\
\text { respeito do resultado da } \\
\text { certificação }\end{array}$ & $\begin{array}{l}\text { Informar a empresa através de e- } \\
\text { mail, quadro de avisos e } \\
\text { monitores sobre o resultado da } \\
\text { certificação. }\end{array}$ & $\begin{array}{l}\text { - Ser aprovado pela } \\
\text { Gerente de Projeto. }\end{array}$ \\
\hline 1.6 .2 & $\begin{array}{l}\text { - Tratar as recomendações } \\
\text { de melhoria identificadas na } \\
\text { auditoria externa }\end{array}$ & $\begin{array}{l}\text { Dar tratamento aos registros } \\
\text { apontados na auditoria externa. }\end{array}$ & $\begin{array}{l}\text { - Ser aprovado pela } \\
\text { Empresa } \\
\text { certificadora. }\end{array}$ \\
\hline
\end{tabular}


VI CIDESPORT/2019

Congresso Internacional

de Desempenho Portuário

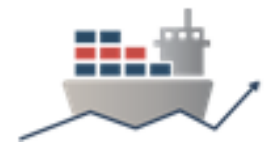

\begin{tabular}{|c|c|c|c|}
\hline 1.6 .3 & $\begin{array}{l}\text { - Registrar as lições } \\
\text { aprendidas }\end{array}$ & $\begin{array}{l}\text { Documentar erros e melhorias } \\
\text { identificadas ao longo do projeto. }\end{array}$ & $\begin{array}{l}\text { - Ser aprovado pela } \\
\text { Gerente de Projeto. }\end{array}$ \\
\hline 1.6 .4 & $\begin{array}{l}\text { - Procedimentos Revisados } \\
\text { e Implantados }\end{array}$ & $\begin{array}{l}\text { - Marco formal da aceitação dos } \\
\text { procedimentos revisados } \\
\text { implantados. }\end{array}$ & $\begin{array}{l}\text { - Ser aprovado pela } \\
\text { Gerente de Projeto. }\end{array}$ \\
\hline 1.6 .5 & $\begin{array}{l}\text { - Norma ISO 9001:2015 } \\
\text { Implantada na Empresa }\end{array}$ & $\begin{array}{l}\text { - Marco formal da finalização da } \\
\text { implantação da norma na } \\
\text { empresa. }\end{array}$ & $\begin{array}{l}\text { - Ser aprovado pela } \\
\text { Gerente de Projeto. }\end{array}$ \\
\hline 1.6 .6 & $\begin{array}{l}\text { - Empresa Certificada na } \\
\text { Norma ISO 9001:2015 }\end{array}$ & $\begin{array}{l}\text { - Marco formal de recebimento da } \\
\text { certificação da empresa. }\end{array}$ & $\begin{array}{l}\text { - Ser aprovado pela } \\
\text { Gerente de Projeto. }\end{array}$ \\
\hline 1.6.7 & - Projeto Concluído & $\begin{array}{l}\text { - Marco formal de conclusão do } \\
\text { projeto. }\end{array}$ & $\begin{array}{l}\text { - Ser aprovado pela } \\
\text { Gerente de Projeto. }\end{array}$ \\
\hline
\end{tabular}

Elaborado pelos autores.

\section{VALIDAR O ESCOPO DO ESTUDO DE CASO}

Este processo teve a responsabilidade de supervisionar cada um dos resultados intermediários e finais do projeto, assim como cada uma de suas entregas. Neste momento a correta inspeção dos subprodutos informou se as entregas estavam de acordo com o planejado, caso estivessem receberiam a aceitação formal do escopo do projeto que pode ser feita através de um Termo de Aceite e caso não estivessem de acordo, medidas deveriam ser tomadas para corrigi-las, o que poderia gerar solicitações de mudanças no escopo. Este processo apesar de simples tem um papel fundamental para o bom andamento e continuidade do projeto. A Figura 06 apresenta o Termo de Aceitação elaborado para o estudo de caso. 
VI CIDESPORT/2019

Congresso Internacional

de Desempenho Portuário

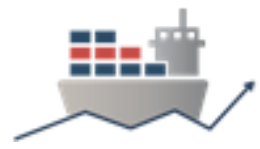

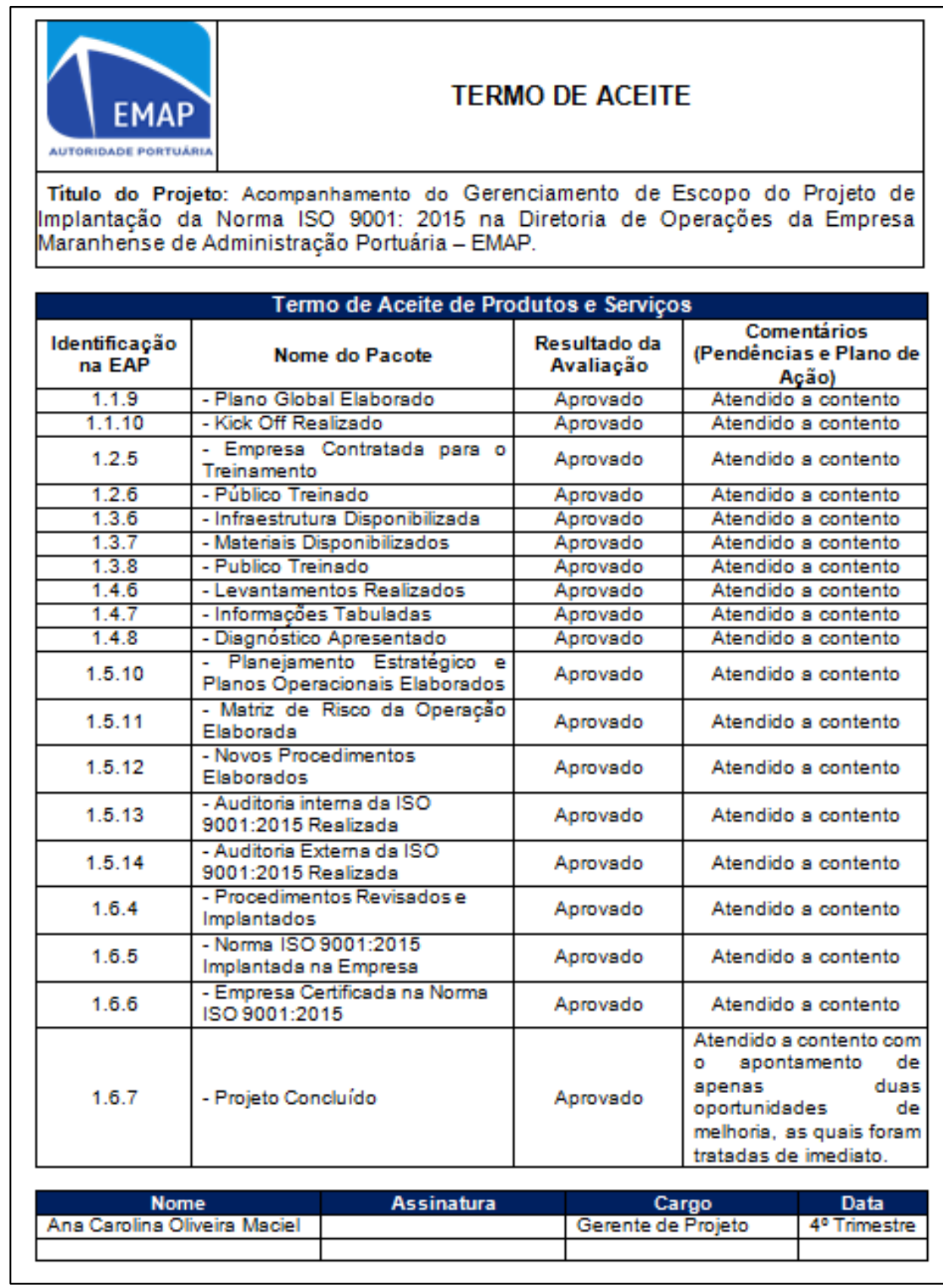

Figura 06 - Termo de Aceite do Projeto.

Elaborado pelos autores.

\section{CONTROLAR O ESCOPO DO ESTUDO DE CASO}

De acordo SOTILLE (2014), o processo de controlar o escopo complementa o desenho do controle integrado de mudanças, responsável por encaminhar e integrar todas as mudanças que afetam o desenvolvimento do projeto, bem como permite que a linha de base do escopo seja atendida durante todo o empreendimento.

\subsection{Formulário de Solicitação de Mudanças}


VI CIDESPORT/2019

Congresso Internacional

de Desempenho Portuário

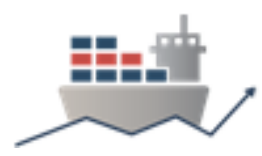

Para uma melhor gestão destas solicitações de mudanças e verificação de seus impactos no projeto foi necessário elaborar um Formulário de Solicitação de Mudança, apresentado na Figura 07, que deve ser analisado pelo gerente de projeto e áreas responsáveis.

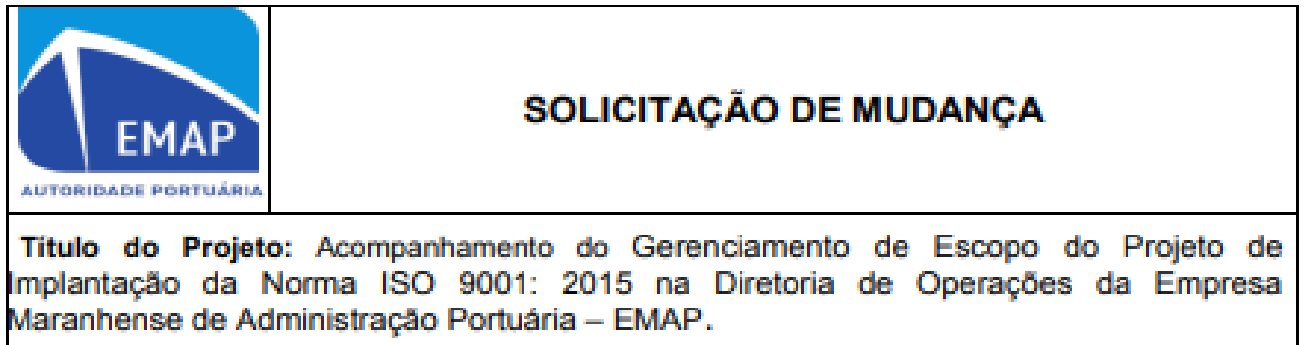

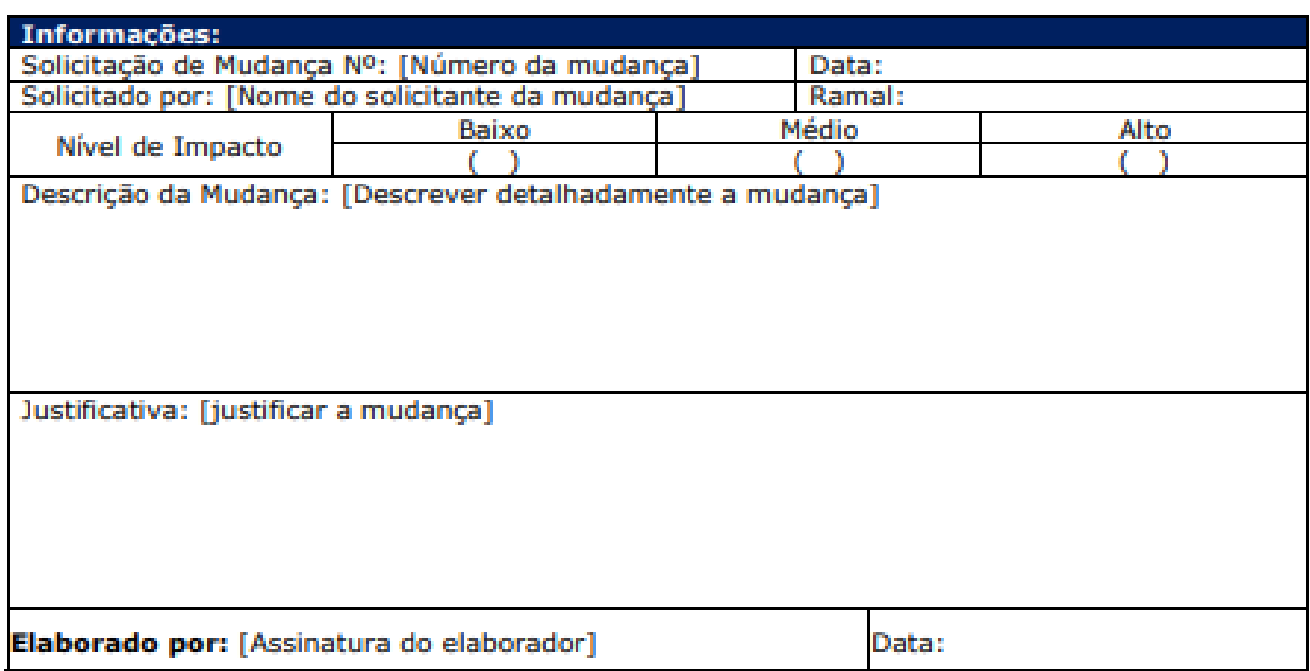

\begin{tabular}{|l|l|}
\hline Parecer do Gerente do Projeto: & \multicolumn{1}{|c|}{ Descrever Impactos Identificados } \\
\hline Escopo: & $\begin{array}{l}\text { [Descrever impactos no escopo, identificando a necessidade de aditivos } \\
\text { contratuais, desvios, etc] }\end{array}$ \\
\hline Cronograma: & $\begin{array}{l}\text { [Descrever impactos no cronograma e a necessidade de uso de alguma } \\
\text { técnica (crashing ou fast tracking)] }\end{array}$ \\
\hline Custo: & [Descrever impactos positivos ou negativos no orçamento] \\
\hline Qualidade: & [Descrever o comprometimento na qualidade das entregas] \\
\hline Outros Projetos: & $\begin{array}{l}\text { [Descrever se a mudança deste projeto impacta outros projetos. O } \\
\text { gerente de projeto pode atuar junto com o Escritório de Projeto (PMO) } \\
\text { para analisar este item] }\end{array}$ \\
\hline Gerente do Projeto: [Assinatura do gerente do projeto] & Data: \\
\hline
\end{tabular}

\begin{tabular}{|c|c|}
\hline Aprovar () Rejeitar ( ) & \\
\hline \multicolumn{2}{|c|}{ Justificar: [justificar a aprovaçāo ou rejeição] } \\
\hline Aprovador: [Assinatura do Aprovador] & Data: \\
\hline
\end{tabular}

Figura 07 - Formulário de Solicitação de Mudança.

Elaborado pelos autores.

\subsection{Fluxo de Análise de Mudanças}


VI CIDESPORT/2019

Congresso Internacional

de Desempenho Portuário

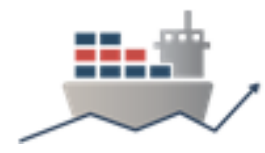

Fez-se necessário ainda, a criação de um fluxo de análise do processo para o controle de mudanças. O fluxo elaborado para este estudo de caso é apresentado na Figura 08.

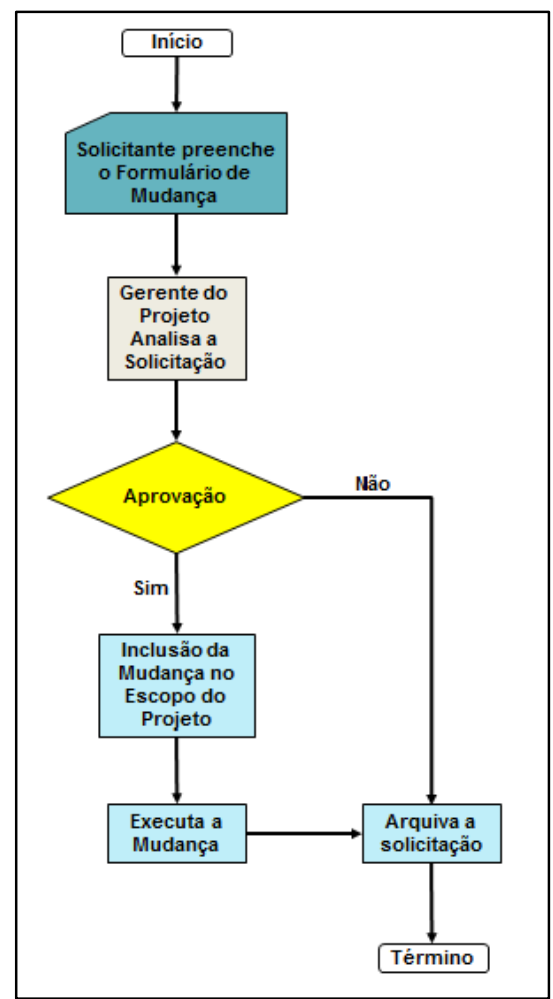

Figura 08 - Fluxo de processo para o controle de mudanças do Projeto.

Elaborado pelos autores.

\section{RESULTADOS OBTIDOS}

Cada um dos objetivos específicos como coletar requisitos necessários, definir o escopo do projeto, criar estrutura analítica do projeto - EAP, criar o dicionário da EAP e elaborar o plano de gerenciamento do escopo traçados para a execução do projeto foram realizados como planejado e de acordo com a metodologia adotada, ou seja, seguindo as recomendações do guia de boas práticas para gerenciamento de projetos o PMBOK 2013 5ed.

A partir dos produtos e resultados gerados ao longo do projeto como o Planejamento Estratégico e Planos Operacionais da EMAP, pode-se afirmar que o objetivo principal deste trabalho que era propor formas de gerenciar o escopo do projeto de implantação da Norma ISO 9001:2015 na Diretoria de Operações da Empresa Maranhense de Administração Portuária, tomando como referência as recomendações do Project Management Institute - PMI foi alcançado.

Para coroar o sucesso do projeto durante sua execução foram desenvolvidas cadeias de apoio à Diretoria de Operação, para solucionar eventuais desvios operacionais.

\section{CONSIDERAÇÕES FINAIS}

Neste trabalho foi possível constatar que as recomendações sobre o gerenciamento de projetos contidas no Guia PMBOK 2013 5ed, de fato colaboraram 


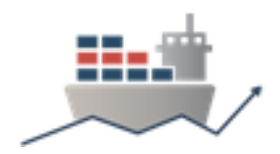

para que a Gerente de Projeto tivesse não apenas uma visão panorâmica, mas também específica da execução de seu projeto, através da utilização de ferramentas, técnicas, metodologias, recursos e procedimentos, o que resultou em um melhor controle das atividades e contribui para uma tomada de decisão mais precisa e assertiva por parte dos gestores, aumentando consideravelmente a probabilidade de sucesso do empreendimento.

Diante do exposto pode-se responder a seguinte questão do trabalho, "Qual o impacto do gerenciamento do escopo sobre o sucesso da implementação do projeto ISO 9001: 2015 na Diretoria de Operações da EMAP? ". As ferramentas de controle de escopo de projeto utilizadas no gerenciamento do empreendimento em questão, contribuíram para a sistematização da execução do mesmo, através do estabelecimento das regras de gerenciamento do escopo ao longo do projeto.

O Termo de Abertura foi importante para a definição dos requisitos do projeto e para a elaboração de outros documentos que auxiliaram na continuidade do trabalho. O Plano de Gerenciamento do Escopo permitiu estabelecer as informações necessárias a condução do escopo do projeto da forma mais adequada possível. A declaração de Escopo do Projeto detalhou em etapas os produtos que deveriam ser entregues, bem como informou o que não estava no escopo do projeto, o que facilitou a criação da Estrutura Analítica de Projeto e o seu Dicionário, os quais facilitaram a visualização e o controle de todas as atividades que deveriam ser executadas e os recursos a serem direcionados para as mesmas. A partir deste maior controle do projeto foi possível fazer a avaliação das entregas, utilizando os critérios de aceitação acordados com os stakeholders envolvidos e formalizar os aceites por meio de um Termo de Aceite. Para o caso de mudanças de escopo foi desenvolvido um formulário de Solicitação de Mudança de Escopo e um fluxo para a correta análise e gestão destas mudanças. Foi elaborado ainda, uma planilha para registro das lições aprendidas.

A metodologia aplicada neste trabalho permitiu que a empresa conhecesse melhor seus processos e suas interações operacionais, mantendo o fluxo de trabalho organizado, englobando todas as atividades de maneira clara e objetiva. A análise de risco facilitou uma avaliação eficaz dos pontos centrais e limites dos processos operacionais e pontos críticos de controle.

Dessa forma pode-se concluir que a aplicação das boas práticas do Guia PMBOK 2013 5ed, no Gerenciamento de Escopo de Projeto da implementação da Norma ISO 9001: 2015 na Diretoria de Operações da EMAP abriu novos horizontes de gerenciamento dentro da empresa, pois os resultados gerados estimularam a produção de novos projetos orientados pelo guia de boas práticas do Project Management Institute - PMI.

\section{REFERÊNCIAS}

ASSOCIAÇÃO BRASILEIRA DE NORMAS TÉCNICAS. NBR ISO 9000: sistema de gestão da qualidade - fundamentos e vocabulário. Rio de Janeiro, 2015.

ASSOCIAÇÃO BRASILEIRA DE NORMAS TÉCNICAS. NBR ISO 9001: sistema de gestão da qualidade - requisitos. Rio de Janeiro, 2015. 
VI CIDESPORT/2019

Congresso Internacional

de Desempenho Portuário

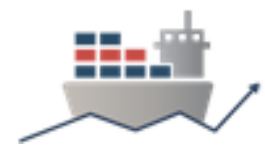

ANUÁRIO ESTATÍSTICO DE 2018. Brasília: ANTAQ, 2019. Anual. Disponível em:< http://web.antaq.gov.br/Anuario/. Acesso em: 20 abr. 2019.

EMPRESA MARANHENSE DE ADMINISTRAÇÃO PORTUÁRIA (EMAP). Autoridade Portuária do Porto do Itaqui. Plano de Desenvolvimento e Zoneamento do Porto do Itaqui - PDZ 2. ed. São Luís/MA, jun. 2012. 194p. Disponível em: < http://www. portodoitaqui.ma.gov.br/pdf/pdz-itaqui.pdf>. Acesso em: 15 fev. 2019.

EMPRESA MARANHENSE DE ADMINISTRAÇÃO PORTUÁRIA - EMAP. Apresentação Comercial da Emap. São Luís: EMAP, 2019. 19 p. Não publicado.

Presidência da República. Decreto $n^{\circ} 8.033$, de 27 de junho de 2013b. Regulamenta o disposto na Lei $n^{\circ} 12.815$, de 5 de junho de 2013 , e as demais disposições legais que regulam a exploração de portos organizados e de instalações portuárias. Diário Oficial [da] União. Brasília, DF, 28 jun. 2013b. Disponível em: <http://www.planalto.gov.br/ccivil_03/_ato2011-2014/2013/Decreto/D8033.htm>. Acesso em: 30 maio 2019.

PROJECT MANAGEMENT INSTITUTE. Um Guia do Conhecimento em Gerenciamento de Projetos: guia PMBOK. 5. ed. Pennsylvania: PMI, 2013.

SOTILLE, M. A. et al. Série Gerenciamento de Projetos: Gerenciamento do Escopo em Projetos. 3. Ed. Rio de Janeiro: FGV, 2014.

VARGAS, Ricardo V. Manual Prático do Plano de Projeto. $5^{\text {a }}$ Edição. Rio de Janeiro: Brasport, 2014. 